Retrospective Evaluation

\title{
Comparative Assessment of Different Percutaneous Endoscopic Interlaminar Lumbar Discectomy (PEID) Techniques
}

Hyeun Sung Kim, MD, PhD, and Jeong Yoon Park, MD, PhD

From: ${ }^{1}$ Department of Neurosurgery, Hurisarang Spine Hospital, Daejeon, South Korea; and ${ }^{2}$ Department of Neurosurgery, Gangnam Severance Hospital, Spine and Spinal Cord Institute, Yonsei University College of Medicine, South Korea

Address Correspondence: Jeong Yoon Park, MD, PhD Department of Neurosurgery Gangnam Severance Hospital Spine and Spinal Cord Institute Yonsei University College of Medicine 211, Eonju-ro Gangnam-gu, Seoul 135-720, South Korea E-mail: spinepjy@gmail.com

Disclaimer: There was no external funding in the preparation of this manuscript.

Conflict of interest: None.

Manuscript received: 01-22-2013 Revised manuscript received: 03-13-2013

Accepted for publication: 03-26-2013

Free full manuscript: www.pain physicianjournal.com
Background: Percutaneous endoscopic lumbar discectomy is a common surgical treatment for lumbar disc herniation, and percutaneous endoscopic interlaminar lumbar discectomy (PEID) is commonly used for direct decompression of L5-S1. Like microdiscectomy, recurrence of herniation after endoscopic discectomy is an important problem. In this study, we aimed to decrease the recurrence after PEID using a new surgical technique.

Objectives: We propose a new surgical technique for reducing the recurrence after PEID for lumbar disc herniation. The new technique uses annular sealing after fragmentectomy. We compared clinical results and recurrent lumbar disc herniation (had radiculopathy and confirmed by MRI) between patients who underwent surgery with and without annular sealing during PEID.

Study Design: Retrospective cohort study of patients undergoing PEID.

Methods: A total of 224 patients with radiculopathy due to L5-S1 disc herniation who were treated by PEID with (91 patients) or without annular sealing (133) were included in this study. We compared the demographic characteristics (age, sex, height, weight, BMI, smoking status, and occupation), clinical results, and recurrence rates between the 2 groups. We classified recurrence according to time period (early recurrence $\leq 6$ months, late recurrence $>6$ months).

Results: The study groups were demographically similar, and substantial improvement in clinical results was noted. There were 5 recurrences (5.5\%) (2 early, 3 late recurrences) in the group with annular sealing, and 18 (13.5\%) (13 early, 5 late recurrences) in the group without annular sealing. Early recurrence rates were significantly higher in the group without sealing ( 2 vs. $13, P=0.029$ ). Increasing age was associated with overall recurrence $(P=0.004)$ and late recurrence $(P=0.008)$, while operative technique correlated with early recurrence $(P=0.026)$.

Limitations: First, this study incorporates a retrospective design. Second, the operations were performed by 2 surgeons. Additionally, this is relatively a short-term follow-up study (mean 19.5 \pm 5.0 months).

Conclusions: Though a learning curve is needed in order to become familiar with PEID, recurrence after PEID was associated with advanced age, and PEID with annular sealing resulted in lower early recurrence rates than without annular sealing. Thus, PEID with annular sealing may be a useful technique for reducing early recurrence.

Key words: Percutaneous endoscopic lumbar discectomy, interlaminar approach, fragmentectomy, recurrence

Pain Physician 2013; 16:359-367 
S ince operative treatment of lumbar disc herniation was first described by Dandy and Mixter in the early 1900s, it has become the most common disease of the spine requiring surgical treatment $(1,2)$. Among the operative methods used for lumbar discectomy, the microdiscectomy technique is considered to be the gold standard procedure for symptomatic lumbar disc herniation which has not improved with conservative management (3).

With the development of high-resolution endoscopes, several kinds of percutaneous endoscopic lumbar discectomy techniques were introduced. These techniques result in less damage to muscular and ligamentous structures, and allow for faster rehabilitation, shorter hospital stays, and earlier return to work by preserving bone and facet structures (4-8). The posterolateral transforaminal approach with percutaneous endoscopic lumbar discectomy is a popular endoscopic technique, though the transforaminal approach to the L5-S1 disc space may be limited due to impediment by the iliac crest, a large L5 transverse process, a large facet joint, or narrowed disc space (9-14). To overcome these obstacles, the percutaneous endoscopic interlaminar lumbar discectomy (PEID) technique was introduced, and PEID became a popular percutaneous endoscopic technique for L5-S1 discectomy because of the direct pathway for decompression (9-12).

Although many studies have shown the efficacy of percutaneous endoscopic discectomy with good clinical outcomes, recurrence after endoscopic discectomy remains an important problem $(4-6,9,12,15,16)$. In this study, we aimed to compare a new surgical technique with conventional PEID to decrease the recurrence of disc herniation after PEID. This new PEID technique uses annular sealing with a bipolar radiofrequency coagulator after fragmentectomy to constrict and reduce the annular fissure. We compared clinical results and recurrence rates between the groups with and without annular sealing during PEID.

\section{Methods}

This is a retrospective cohort study of patients who underwent PEID using one of the 2 different operative techniques. We enrolled 224 consecutive patients who underwent PEID between January 2008 and February 2010. Patients were divided into 2 groups: Group 1 underwent PEID with annular sealing (91 patients) and Group 2 underwent PEID without annular sealing (133 patients). Indications for surgical treatment were unilateral radicular pain in the leg that did not respond to 8 weeks of conservative management and imaging (computed tomography [CT] and magnetic resonance imaging [MRI]), which suggested posterolateral ruptured disc herniation at the L5-S1 level that corresponded with the clinical symptoms. Only sequestrectomy or fragementectomy was performed, and patients who needed extensive discectomy (broad base disc herniation, disc herniation with stenosis, calcified disc herniation) and patients who previously underwent surgery at the same vertebral level, and less than postoperatively one year follow-up were excluded. All operations were performed randomly, and there were no differences in indications between the groups. This project was approved by the Institutional Review Board of Gangnam Severance Hospital, Yonsei University College of Medicine (No 3-2012-0166).

\section{Operative Techniques: Annular Sealing during PEID}

Sequestrectomy and fragmentectomy of ruptured particles through annular defects are typically performed using the PEID technique developed by Choi et al and Ruetten et al (9-12). Usually during PEID, since surgeons cannot use a knife through endoscopy, a punch was used to open the annulus, as it is well known that annular defect size is associated with recurrent disc herniation. In order to minimize the annular defects or fissures, we used a dissector in attempt to open the annulus rather than a punch in both groups. In Group 2 (without annular sealing), the cannula and scope were removed after extracting the ruptured particles. In Group 1 (with annular sealing), the circumference of the annular fissure was subsequently coagulated by more than 10 times, using bipolar radiofrequency (Ellman Corp., New York, NY, USA) toward the annular defect (Fig. 1). Radiofrequency was adjusted to 15 watts and coagulation duration was timed to less than one second per coagulation. After constriction, tightening and reduction of the annular fissure were observed, the scope and cannula were gradually removed.

\section{Outcomes Assessment}

We compared the demographic characteristics (age, sex, height, weight, BMI, smoking status, and occupation) and clinical results with the visual analog scale (VAS) for leg and Oswestry Disability Index (ODI) of the 2 groups. Occupations were classified according to the International Standard Classification of Occupations into 10 categories (manager, professional, associate professional, clerical support worker, sales worker, 


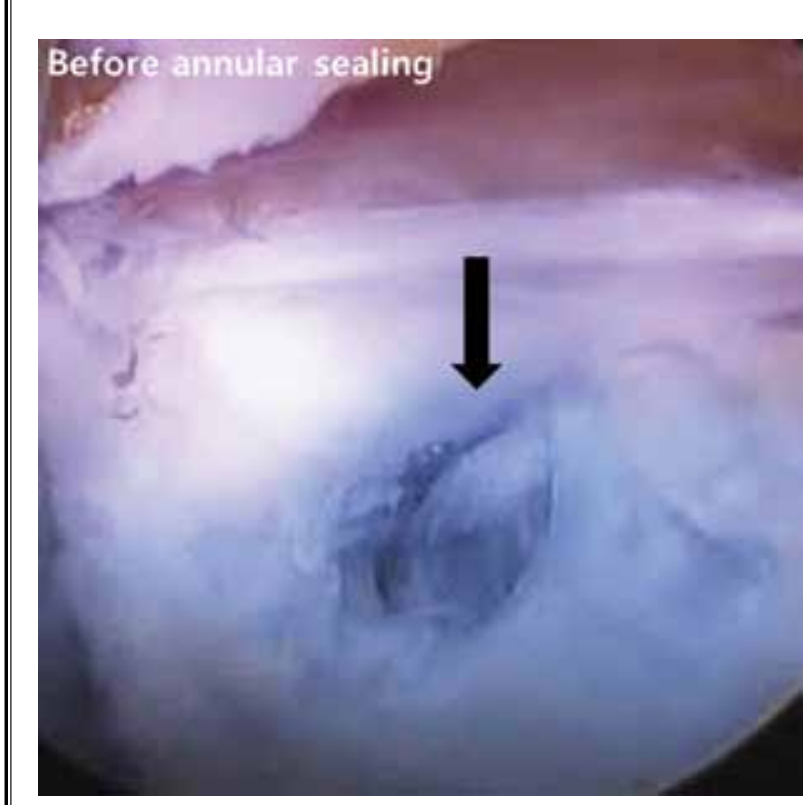

Fig. 1. Pictures during PEID with annular sealing. We can observe annular defect (black arrow) change before, during, and after annular sealing. .
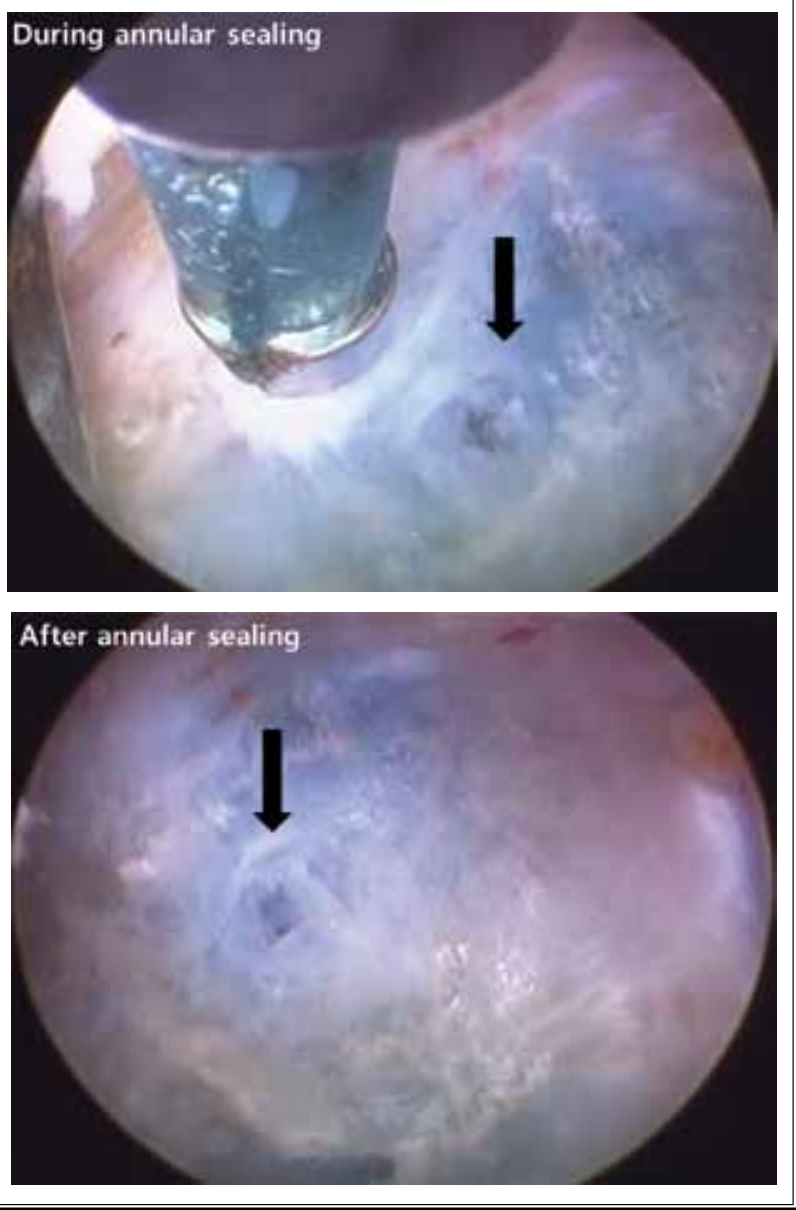

skilled agricultural worker, craft worker, machine operator, elementary occupation, and armed forces occupations) as well as student, housewife, and none. There were no patients with disability. We also compared the recurrence rates according to the operative technique; however, the definition of recurrence has historically been varied according to the symptom-free period and location (15,17-21). In this study, we obtained an immediate postoperative MRI for all patients. Recurrence was classified as disc herniation on the same side and level as the primary operative site after successful initial removal of the protruding disc and a pain-free interval after surgery, which was revealed on an immediate postoperative MRI. In addition, recurrence was classified according to the time period, with early recurrence at $\leq 6$ months and late recurrence at $>6$ months postsurgical intervention.

\section{Statistical Analysis}

Statistical comparisons were based on the observed and recorded follow-up data. SPSS software for Windows (version 15.0K; SPSS, Chicago, IL, USA) was used for the analysis. For statistical comparisons between groups, chi-square tests and independent t-tests were used. To determine the relationships between recurrence and all other measured parameters, Spearman's rho and Kendall's tau bivariate correlation tests were used. $P$-values of $<0.05$ were considered to be statistically significant.

\section{Results}

\section{Demographic Characteristics}

The demographic characteristics of the 2 groups are summarized in Table 1 . The mean age of patients 
Table 1. Demographic characteristics

\begin{tabular}{|c|c|c|c|c|c|c|c||}
\hline $\begin{array}{c}\text { Operative } \\
\text { technique }\end{array}$ & $\begin{array}{c}\text { Mean age } \\
\text { (years) }\end{array}$ & Male/Female & $\begin{array}{c}\text { Mean F/U period } \\
\text { (months) }\end{array}$ & Height (cm) & Weight (kg) & BMI & Smoking (\%) \\
\hline Total (224) & $41.5 \pm 12.9$ & $137 / 87$ & $19.5 \pm 5.0$ & $165.8 \pm 17.9$ & $65.4 \pm 14.2$ & $23.4 \pm 3.3$ & $129(57.6)$ \\
\hline $\begin{array}{c}\text { PEID with sealing } \\
(91,40.6 \%)\end{array}$ & $41.9 \pm 13.1$ & $58 / 33$ & $19.5 \pm 4.7$ & $166.7 \pm 12.8$ & $65.8 \pm 15.1$ & $23.6 \pm 3.6$ & $55(60.4)$ \\
\hline $\begin{array}{c}\text { PEID without sealing } \\
(133,59.4 \%)\end{array}$ & $41.3 \pm 12.9$ & $79 / 54$ & $19.5 \pm 5.2$ & $165.2 \pm 20.7$ & $65.1 \pm 13.6$ & $23.3 \pm 3.1$ & $74(55.6)$ \\
\hline
\end{tabular}

Table 2. Patient occupations

\begin{tabular}{|c|c|c|c|c|c|c|c|c|}
\hline Operative technique & $\begin{array}{c}\text { Clerical } \\
\text { support worker }\end{array}$ & $\begin{array}{l}\text { Elementary } \\
\text { occupation }\end{array}$ & $\begin{array}{l}\text { Machine } \\
\text { operator }\end{array}$ & Housewife & Craft worker & Student & Others* & None \\
\hline Total (224) & 59 & 27 & 9 & 72 & 8 & 14 & 20 & 15 \\
\hline PEID with sealing (91) & 27 & 12 & 3 & 24 & 6 & 9 & 3 & 7 \\
\hline $\begin{array}{c}\text { PEID without sealing } \\
\text { (133) }\end{array}$ & 32 & 15 & 6 & 48 & 2 & 5 & 17 & 8 \\
\hline
\end{tabular}

* sales worker, armed force occupation, policeman, associate professional, and assembler.

Table 3. Clinical results and recurrence rates

\begin{tabular}{|c|c|c|c|c|c|c|c||}
\hline Operative technique & $\begin{array}{c}\text { Pre-VAS } \\
(\mathbf{l e g})\end{array}$ & $\begin{array}{c}\text { Post-VAS } \\
(\mathbf{l e g})\end{array}$ & Pre-ODI & Post-ODI & $\begin{array}{c}\text { Total } \\
\text { recurrence (\%) }\end{array}$ & $\begin{array}{c}\text { *Early } \\
\text { recurrence (\%) }\end{array}$ & $\begin{array}{c}\text { Late } \\
\text { recurrence } \\
(\%)\end{array}$ \\
\hline Total (224) & $7.8 \pm 0.6$ & $2.0 \pm 0.8$ & $55.6 \pm 7.4$ & $18.8 \pm 3.2$ & $23(10.3)$ & $15(6.7)$ & $8(3.6)$ \\
\hline PEID with sealing (91) & $7.7 \pm 0.6$ & $1.9 \pm 0.8$ & $54.8 \pm 8.6$ & $18.4 \pm 3.8$ & $5(5.5)$ & $2(2.2) \dagger$ & $3(3.3)$ \\
\hline PEID without sealing (133) & $7.9 \pm 0.6$ & $2.0 \pm 0.8$ & $55.4 \pm 9.2$ & $19.2 \pm 3.2$ & $18(13.5)$ & $13(9.8) \dagger$ & $5(3.8)$ \\
\hline
\end{tabular}

$\dagger$ Between groups comparisons using Chi-Squared tests $(\mathrm{p}=0.029)$, and Spearman correlation coefficients for correlations according to operative technique (Spearman's $\mathrm{rs}=0.191, \mathrm{P}=0.004) .{ }^{*}$ Early recurrence $\leq 6$ months.

was $41.5 \pm 12.9$ years and the mean of the follow-up period was $19.5 \pm 5.0$ months. There were 91 patients in the PEID with annular sealing group (40.6\%) and 133 patients in the PEID without annular sealing group $(59.4 \%)$ (Table 1). Demographic characteristics (age, sex, height, weight, BMI, and smoking status) did not differ between the groups (Table 1). Occupations of patients are summarized in Table 2, with clerical support workers and housewives being the most common.

\section{Clinical Results and Recurrence Rates}

Table 3 summarizes the clinical results and recurrence rates. All clinical data had significantly improved at the final follow-up (VAS improved from 7.8 to 2.0, ODI improved from 55.6 to 18.8) and did not differ between the groups (Table 3). There were no flare-up symptoms associated with radiofrequency for both groups. A total of 23 patients (10.3\%) experienced re- currence and there were no significant differences in the total or late recurrence between the groups (total recurrence $5[5.5 \%$ ] versus 18 [13.5\%], late recurrence 3 [3.3\%] versus 5 [3.8\%] in groups with and without annular sealing, respectively) (Table 3). Early recurrence, on the other hand, was significantly more common in the group without annular sealing (2 [2.2\%] versus $13[9.8 \%], P=0.029$ ) (Table 3). Among the 91 cases of "PEID with sealing," 51 cases were performed by the first author and 40 cases were performed by the second author. There were 2 cases of early recurrence ( $1 / 1$ for each operator), and 3 cases of late recurrence (2/1 for each operator). Among the 133 cases of "PEID without sealing," 72 cases were performed by the first author and 61 cases performed by the second author. There were 5 cases of early recurrence (2/3 for each operator), and 13 cases of late recurrence (7/6 for each operator). There was no statistical difference in the recurrence 
rate according to the operator. Early and late recurrences occurred postoperatively at 1.6 months and 17.1 months, respectively. The mean age of patients who experienced early recurrence was $46.2 \pm 13.5$ and late recurrence was $53.4 \pm 10.2$ years.

Among the demographic characteristics, increasing age was correlated with higher overall recurrence (Spearman's $r s=0.157, P=0.004$ ) and late recurrence (Spearman's rs $=0.176, P=0.008$ ) (Table 4). Early recurrence was correlated with the operative technique (Spearman's rs $=0.149, P=0.026$ ) (Table 4). None of the other characteristics analyzed (sex, height, weight, BMI, smoking, and occupations) had any correlation with recurrence. Among the 23 patients that experienced recurrence, 9 patients underwent microdiscectomy, 11 patients underwent repeat PEID, and 3 patients opted for conservative management.

\section{Discussion}

From this study, we observed that $5.5 \%$ of the subjects experienced recurrences in PEID with annular sealing, and $13.5 \%$ in PEID without annular sealing. Early recurrence rates were higher especially in the group without sealing. Age was correlated with overall recurrence and late recurrence, while operative technique correlated with only early recurrence.

Among the group treated with endoscopic discectomy, the transforaminal approach was performed more commonly, but the transforaminal approach with percutaneous endoscopic lumbar discectomy needs a lateral entry route and makes accessing the intervertebral space difficult at L5-S1 because of the iliac crest (8-10,20-23). Recently, PEID is a more commonly used discectomy technique to access the L5-S1 than the transforaminal approach for endoscopic discectomy (10-12,22-25). Additionally, while using an interlaminar approach with percutaneous endoscopic lumbar discectomy for L5-S1, resection of the intradiscal nucleus material is frequently limited due to a divergence between the interlaminar window and the intervertebral space (8-10). Because of these limitations, percutaneous endoscopic lumbar discectomy is often used for the removal of ruptured particles using sequestrectomy or fragementectomy instead of aggressive discectomy. Endoscopic discectomy is a minimally invasive procedure that reduces damage to the muscular and ligamentous structures thus allowing for faster rehabilitation, shorter hospital stay, and earlier return to work by preserving the bone and facet structures. Recurrence is the most important complication associated with PEID $(4-6,9,10,22)$.
Table 4. Correlation coefficients between recurrence $\&$ characteristics

\begin{tabular}{|l|l|l|}
\hline & $\begin{array}{l}\text { Pearson } \\
\text { correlation }\end{array}$ & $\boldsymbol{P}$-value \\
\hline Total recurrence - Age & 0.157 & 0.004 \\
\hline $\begin{array}{l}\text { Early recurrence - Operative } \\
\text { Technique }\end{array}$ & 0.149 & 0.026 \\
\hline Late recurrence - Age & 0.176 & 0.008 \\
\hline
\end{tabular}

PEID uses a direct pathway for decompression and is more similar to sequestrectomy or fragementectomy than the posterolateral transforaminal approach with percutaneous endoscopic lumbar discectomy (5). Because PEID is a relatively a new procedure that usually requires a learning curve in order to get accustomed to PEID and the different instruments and anatomical view, there are few reports about the recurrence rates (range 0.1 to $6.6 \%$ ) after PEID versus recurrence rates after conventional sequestrectomy (range 2 to 18\%) $(9,12,18,22,26-31)$. In our study, we report a recurrence rate of $10.3 \%$, which is higher than in the previous reports $(9,11,12)$. However, previous studies were not consistent with the criteria used to classify the recurrences. Lee et al (15) defined recurrences that occurred within 2 weeks as operative failures, and Ruetten et al (10) only reported recurrences that occurred within 6 months of surgery. According to Kim et al (16), recurrence only occurred after at least a 2-week symptomfree interval. Additionally, Suk et al (17) defined recurrence as disc herniation at the same vertebral level, whether ipsilateral or contralateral, with a pain-free interval greater than 6 months. Due to the use of these variable definitions of recurrent lumbar disc herniation, recurrence rates are difficult to compare between studies. To determine the true recurrence rate in this study, we obtained immediate postoperative MRIs of all patients and defined recurrence as disc protrusion on the same side and level as the initial operative site after a successful pain-free interval without pain medication. In addition, recurrence after percutaneous endoscopic lumbar discectomy usually occurred within 6 months; therefore, recurrences were classified according to the recurrence period, with early recurrence $\leq 6$ months after PEID, and late recurrence $>6$ months after PEID $(10,15,16)$. We observed a total recurrence rate of $10.3 \%, 6.7 \%$ of which were early and $3.6 \%$ of which were late recurrences (Table 3 ). Our early recurrence rate was similar to that of previous studies $(10,15,16)$.

The purpose of this study was to introduce a new surgical technique for decreasing the recurrence of disc 
herniation after PEID, especially early recurrence which is more common than late recurrence. We compared the demographic characteristics (sex, height, weight, BMI, smoking status, and occupation), which can influence recurrence rates, and found that age was the only factor significantly correlated with the total and late recurrence, while early recurrence was reduced by using this new operative technique (Table 4). As age increased, total and late recurrence rates increased as well, which is in agreement with the previous data showing that patients with marked disc degeneration were more likely to experience recurrent herniation (32). Therefore, unlike early recurrence, late recurrence may not be affected by the operative technique. Our results show that early recurrence was decreased by annular sealing during PEID.

It is well known that annular defect size is associated with recurrent disc herniation (33-35). During PEID, surgeons cannot use a knife through the endoscopy, so a punch incision was usually used to open the annulus. In order to minimize annular defects or fissures, the authors tried not to use a punch incision to open the annulus and used a dissector to open the annulus, and did the annular sealing technique to minimize annular defects. After removing the ruptured particles, the perimeter of the annular fissure was coagulated with bipolar radiofrequency more than 10 times (Ellman Corp., New York, NY) toward the annular defect. It has been shown that in order to decrease the recurrence rates, the annular defect must be reduced (33-35). Previous studies have also demonstrated that radiofrequency heating of annular disruptions can lead to improvements in pain control (36-39). Although our study is retrospective, annular sealing was performed randomly due to uncertainty regarding the safety of using multiple bipolar radiofrequency treatments during PEID. For example, heating injury may occur if the radiofrequency probe was damaged despite cold saline irrigation, although a previous study reported that temperatures reaching the neural foramina and epidural space were low enough to avoid nerve damage. The safety of using bipolar radiofrequency during PEID is already accepted for endoscopic spine surgeons $(11,12,37,40-43)$. In clinical results about pain score, there were no statistical differences between groups. In the previous studies, it is well known that radiofrequency heating of annular disruptions can lead to improvements in pain control (36-39). However, from this study, we observed that annular sealing during PEID did not affect the clinical results, and it only limits the early recurrence after PEID.

We obtained an immediate postoperative MRI on all patients to confirm sufficient constriction of the annulus (Figs. 2 and 3), and there was no evidence of heat injury. After this study, we routinely performed annular sealing after PEID. In addition, it is well known that radiofrequency devices shrink or ablate tissue, and make the tissue itself smaller $(18,37,44)$. If we use the
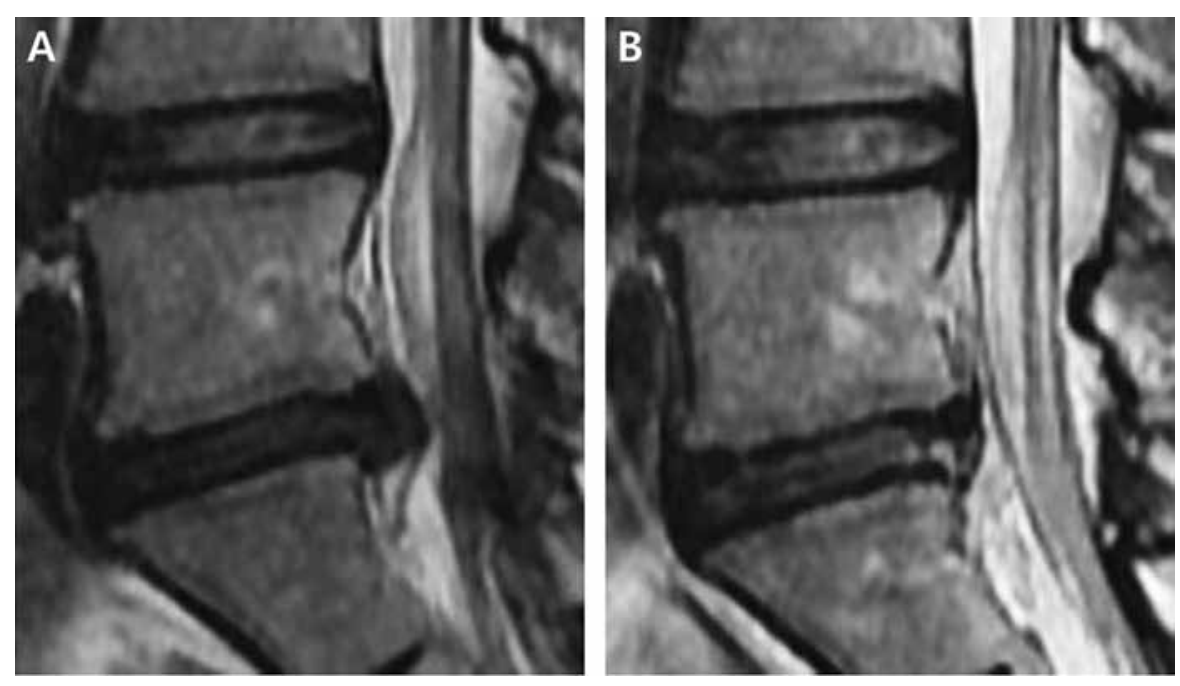

Fig. 2. Pre-operative (A) and immediately postoperative (B) sagittal T2-weighted MRI of a 32-year-old woman who underwent PEID and annular sealing with a bipolar radiofrequency coagulator. On immediate postoperative MRI (B) we can see sufficient constriction of the annulus. 

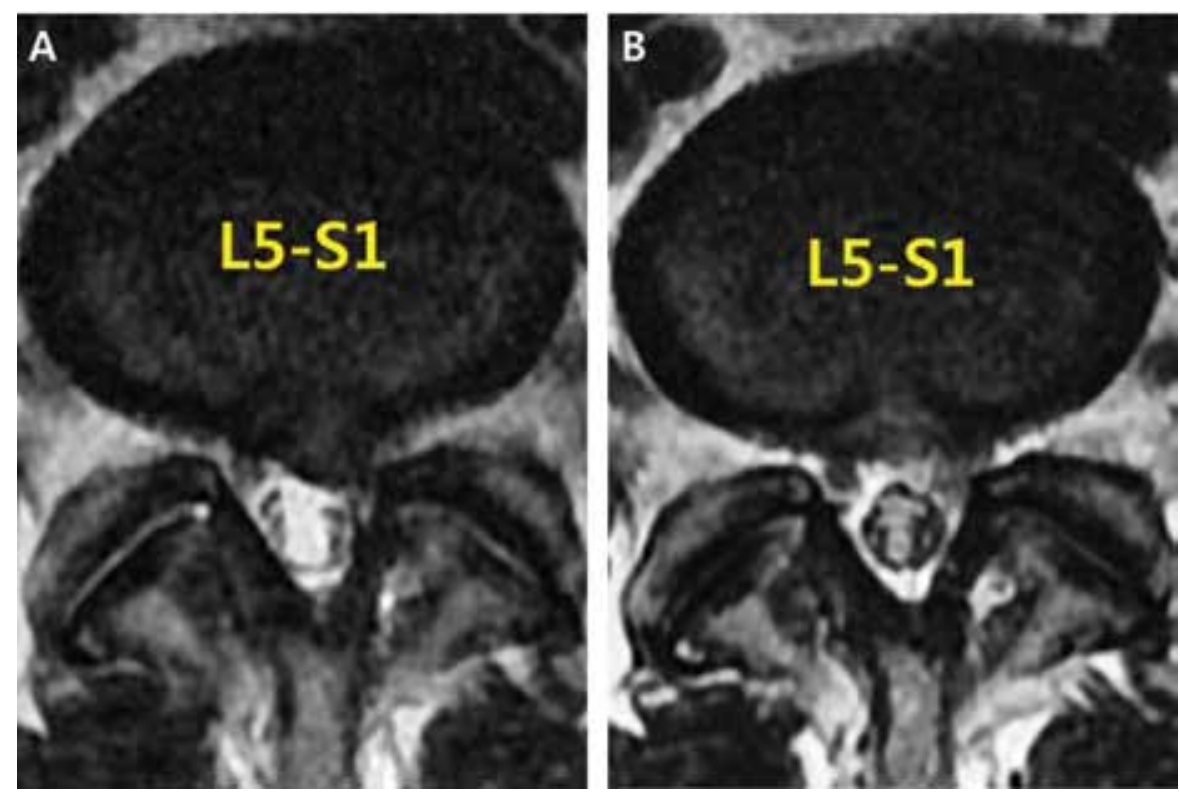

Fig. 3. Pre-operative (A) and immediate postoperative (B) axial T2-weighted MRI of a 32-year-old woman who underwent PEID and annular sealing with a bipolar radiofrequency coagulator. On immediate postoperative MRI (B), we can see sufficient constriction of the annulus.

radiofrequency device directly on an annular defect, defect size will increase rather than decrease. As we describe the operative techniques, the annulus sealing technique only coagulates the circumference of the annulus defect toward the defect, and is not used at the defect directly (Fig. 1). By only coagulating around the defect, we can stabilize and tighten the surrounding loose annular fiber, and we can achieve an effect that decreased the annular defect. There is a possibility that it is only a phenomenon that looks like a decrease of the annular defect, though not an actual decrease. To determine the actual decrease in radiofrequency coagulation of the annular defect, we need further histological studies. Though it is not an actual decrease, we consider that the annular sealing technique can reduce early recurrence during PEID.

There are several limitations to our study. This study is retrospective in its design, and prospective studies will be needed to confirm our data regarding the effects of annular sealing during PEID. The operations were performed by 2 surgeons. In addition, PEID is a relatively new procedure, and thus usually requires a learning curve, and level of skill can influence the recurrence. However, both surgeons in this study had more than 2 years of experience, and before this study, they had already operated on more than 100 PEID cases. Additionally, this is a short-term follow-up study. To know the safety and persisting effect of the annular sealing technique by radiofrequency coagulation, we need further studies with long-term follow-up. In spite of these limitations, our results show that annular sealing during PEID can reduce the early recurrence of disc herniation.

\section{Conclusion}

Total and late recurrence of disc herniation after PEID is associated with advanced age. The annular sealing technique after fragmentectomy resulted in a lower early recurrence rate compared to PEID without annular sealing. This new operative technique may be helpful in reducing the early recurrence of lumbar disc herniation. 


\section{References}

1. Dandy WE. Loose cartilage from intervertebral disk simulating tumor of the spinal cord. By Walter E. Dandy, 1929. Clin Orthop Relat Res 1989; 238:4-8.

2. Parisien RC, Ball PA. William Jason Mixter (1880-1958). Ushering in the "dynasty of the disc." Spine 1998; 23:2363-2366.

3. Williams RW. Microlumbar discectomy. A 12-year statistical review. Spine 1986; 11:851-852.

4. Kambin P, Brager MD. Percutaneous posterolateral discectomy. Anatomy and mechanism. Clin Orthop Relat Res 1987; 223:145-154

5. Kambin P, O’Brien E, Zhou L, Schaffer JL. Arthroscopic microdiscectomy and selective fragmentectomy. Clin Orthop Relat Res 1998; 347:150-167.

6. Schaffer JL, Kambin P. Percutaneous posterolateral lumbar discectomy and decompression with a 6.9-millimeter cannula. Analysis of operative failures and complications. J Bone Joint Surg Am 1991; 73:822-831.

7. Hirsch JA, Singh V, Falco FJ, Benyamin RM, Manchikanti L. Automated percutaneous lumbar discectomy for the contained herniated lumbar disc: A systematic assessment of evidence. Pain Physician 2009; 12:601-620.

8. Singh V, Manchikanti L, Benyamin RM, Helm S, Hirsch JA. Percutaneous lumbar laser disc decompression: A systematic review of current evidence. Pain Physician 2009; 12:573-588.

9. Choi G, Raiturker PP, Lee S, Chae Y Percutaneous endoscopic interlaminar discectomy for intracanalicular disc herniations at $\mathrm{L}_{5}-\mathrm{S}_{1}$ using a rigid working channel endoscope. Neurosurgery 2006; 58:ONS59-68.

10. Ruetten S, Komp M, Godolias G. A New full-endoscopic technique for the interlaminar operation of lumbar disc herniations using 6- $\mathrm{mm}$ endoscopes: Prospective 2-year results of 331 patients. Minim Invasive Neurosurg 2006; 49:80-87.

11. Ruetten S, Komp M, Merk H, Godolias G. Use of newly developed instruments and endoscopes: Full-endoscopic resection of lumbar disc herniations via the interlaminar and lateral transforaminal approach. J Neurosurg Spine 2007; 6:521-530.

12. Ruetten S, Komp M, Merk H, Godolias G. Full-endoscopic interlaminar and transforaminal lumbar discectomy versus conventional microsurgical tech- nique: A prospective, randomized, controlled study. Spine 2008; 33:931-939.

13. Ruetten S, Komp M, Merk H, Godolias G. Recurrent lumbar disc herniation after conventional discectomy: A prospective, randomized study comparing full-endoscopic interlaminar and transforaminal versus microsurgical revision. J Spinal Disord Tech 2009; 22:122-129.

14. Mirkovic SR, Schwartz DG, Glazier KD. Anatomic considerations in lumbar posterolateral percutaneous procedures. Spine 1995; 20:1965-1971.

15. Lee S, Kang BU, Ahn Y, Choi G, Choi Y, Ahn KU, Shin S, Kang H. Operative failure of percutaneous endoscopic lumbar discectomy: A radiologic analysis of 55 cases. Spine 2006; 31:E285-E290.

16. Kim JM, Lee SH, Ahn Y, Yoon DH, Lee CD, Lim ST. Recurrence after successful percutaneous endoscopic lumbar discectomy. Minim Invasive Neurosurg 2007; $50: 82-85$.

17. Suk KS, Lee HM, Moon SH, Kim NH. Recurrent lumbar disc herniation: results of operative management. Spine 2001; 26:672-676.

18. Thomé C, Barth M, Scharf J, Schmiedek P. Outcome after lumbar sequestrectomy compared with microdiscectomy: A prospective randomized study. J Neurosurg Spine 2005; 2:271-278.

19. Davis RA. A long-term outcome analysis of 984 surgically treated herniated lumbar discs. J Neurosurg 1994; 80:415-421.

20. Lee JK, Amorosa L, Cho SK, Weidenbaum M, Kim Y. Recurrent lumbar disk herniation. J Am Acad Orthop Surg 2010; 18:327-337.

21. Moliterno JA, Knopman J, Parikh K, Cohan JN, Huang QD, Aaker GD, Grivoyannis AD, Patel AR, Härtl R, Boockvar JA. Results and risk factors for recurrence following single-level tubular lumbar microdiscectomy. ] Neurosurg Spine 2010; 12:680-686.

22. Chen HT, Tsai CH, Chao SC, Kao TH, Chen YJ, Hsu HC, Shen CC, Tsou HK. Endoscopic discectomy of $\mathrm{L}_{5}-\mathrm{S}_{1}$ disc herniation via an interlaminar approach: Prospective controlled study under local and general anesthesia. Surg Neurol Int 2011; 2:93.

23. Chumnanvej S, Kesornsak W, Sarnvivad $P$, Paiboonsirijit S, Kuansongthum V. Full endoscopic lumbar discectomy via interlaminar approach: 2-year results in Ramathibodi Hospital. J Med Assoc Thai 2011; 94:1465-1470.
24. Kim CH, Chung CK. Endoscopic interlaminar lumbar discectomy with splitting of the ligament flavum under visual control. J Spinal Disord Tech 2012; 25:210-217.

25. Kim $\mathrm{CH}$, Chung $\mathrm{CK}$, Jahng TA, Yang HJ, Son YJ. Surgical outcome of percutaneous endoscopic interlaminar lumbar diskectomy for recurrent disk herniation after open diskectomy. J Spinal Disord Tech 2012; 25:E125-133.

26. Schick U, Elhabony R. Prospective comparative study of lumbar sequestrectomy and microdiscectomy. Minim Invasive Neurosurg 2009; 52:180-185.

27. Wenger M, Mariani L, Kalbarczyk A, Gröger U. Long-term outcome of 104 patients after lumbar sequestrectomy according to Williams. Neurosurgery 2001; 49:329-334.

28. Rogers LA. Experience with limited versus extensive disc removal in patients undergoing microsurgical operations for ruptured lumbar discs. Neurosurgery 1988; 22:82-85.

29. Barth $M$, Weiss $C$, Thomé $C$. Two-year outcome after lumbar microdiscectomy versus microscopic sequestrectomy: Part 1: Evaluation of clinical outcome. Spine 2008; 33:265-272.

30. McGirt MJ, Ambrossi GL, Datoo G, Sciubba DM, Witham TF, Wolinsky J, Gokaslan ZL, Bydon A. Recurrent disc herniation and long-term back pain after primary lumbar discectomy: Review of outcomes reported for limited versus aggressive disc removal. Neurosurgery 2009; 64:338-344.

31. Fakouri B, Patel V, Bayley E, Srinivas S. Lumbar microdiscectomy versus sequesterectomy/free fragmentectomy: A long-term ( $>2$ y) retrospective study of the clinical outcome. J Spinal Disord Tech 2011; 24:6-10.

32. Cinotti G, Roysam GS, Eisenstein SM, Postacchini F. Ipsilateral recurrent lumbar disc herniation. A prospective, controlled study. J Bone Joint Surg Br 1998; 8o:825-832.

33. Chiang C, Cheng C, Sun J, Liao C, Wang $Y$, Tsuang $Y$. The effect of a new anular repair after discectomy in intervertebral disc degeneration: An experimental study using a porcine spine model. Spine 2011; 36:761-769.

34. Natarajan RN, Andersson GB, Patwardhan AG, Verma S. Effect of annular incision type on the change in biomechanical properties in a herniated lumbar 
intervertebral disc. J Biomech Eng 2002; 124:229-236.

35. Zöllner J, Rosendahl T, Herbsthofer B, Humke T, Eysel P. The effect of various nucleotomy techniques on biomechanical properties of the intervertebral disk. Z Orthop Grenzgeb 1999; 137:206-210.

36. Finch PM, Price LM, Drummond PD. Radiofrequency heating of painful annular disruptions: One-year outcomes. J Spinal Disord Tech 2005; 18:6-13.

37. Kapural L, Mekhail N, Hicks D, Kapural M, Sloan S, Moghal N, Ross J, Petrinec D. Histological changes and temperature distribution studies of a novel bipolar radiofrequency heating system in degenerated and nondegenerated human cadaver lumbar discs. Pain Medicine 2008; 9:68-75.

38. Singh V, Piryani C, Liao K. Role of percutaneous disc decompression using coblation in managing chronic disco- genic low back pain: A prospective, observational study. Pain Physician 2004; 7:419-425.

39. Boswell MV, Trescot AM, Datta S, Schultz DM, Hansen HC, Abdi S, Sehgal N, Shah RV, Singh V, Benyamin RM, Patel VB, Buenaventura RM, Colson JD, Cordner HJ, Epter RS, Jasper JF, Dunbar E, Atluri SL, Bowman RC, Deer TR, Swicegood JR, Staats PS, Smith HS, Burton AW, Kloth DS, Giordano J, Manchikanti L. Interventional techniques: Evidencebased practice guidelines in the management of chronic spinal pain. Pain Physician 2007; 10:7-111.

40. Peng CW, Yeo W, Tan SB. Percutaneous endoscopic lumbar discectomy: Clinical and quality of life outcomes with a minimum 2 year follow-up. J Orthop Surg Res 2009; 4:20.

41. Peng CW, Yeo W, Tan SB. Percutaneous endoscopic discectomy: Clinical results and how it affects the quality of life. J Spinal Disord Tech 2010; 23:425-430.

42. Tsou PM, Alan Yeung C, Yeung AT. Posterolateral transforaminal selective endoscopic discectomy and thermal annuloplasty for chronic lumbar discogenic pain: A minimal access visualized intradiscal surgical procedure. Spine J 2004; 4:564-573.

43. Pace C, Reyna J, Schlicht C. Percutaneous disc decompression for the treatment of lumbar spinal stenosis. Pain Physician 2003; 6:509-512.

44. Petersohn JD, Conquergood LR, Leung $M$. Acute histologic effects and thermal distribution profile of disc biacuplasty using a novel water-cooled bipolar electrode system in an in vivo porcine model. Pain Medicine 2008; 9:26-32. 
